\title{
The prevalence of hyperglycemia in critically ill children admitted in PICU
}

\author{
Jain $\mathbf{H}^{\mathbf{1}}$, Arya $\mathrm{S}^{\mathbf{2}}$, Mandloi $\mathbf{R}^{\mathbf{3}}$ \\ ${ }^{1}$ Dr. Hemant Jain, Professor, ${ }^{2}$ Dr Sunil Arya, Assistant professor, ${ }^{3}$ Dr Rashika Mandloi, P.G Student. All are affiliated \\ with Department of Pediatrics, M. G. M. Medical College, Indore, MP, India.
}

Address for Correspondence: Dr Sunil Arya, Assistant Professor, Department of Pediatrics, M. G. M. Medical College, Indore, MP, India. E Mail- drsunilarya22@gmail.com

\begin{abstract}
Background: Stress hyperglycemia is mainly due to increased gluconeogenesis and glycogenolysis \& insulin resistance. Longer duration of hyperglycemia during hospital stay is known to have adverse outcome. Aim of Study: To study the prevalence of hyperglycemia and its association with PICU mortality and morbidity in terms of duration of PICU stay. Design: Prospective Observational study. Method: All critically ill children belonging to age group of 1 month to 14 years, admitted in PICU from 1st May 2011 to 15th September 2011 over a period of four and a half months. Children were followed throughout their hospital stay and outcome in terms of mortality and duration of PICU stay were noted. Blood glucose levels weredone every 3 hourly during the first 48 hours of PICU admission. Highest blood glucose level in the first 48 hours was defined as the peak glucose level. The mean of glucose values of first 24 and first 48 hours were calculated. Result: Prevalence of hyperglycemia was 58\%. Mortality rate was higher in the hyperglycemic patients $(56 \%)$ as compared to normoglycemics $(14 \%)$ and overall mortality $(36 \%)$. The $p$ value for difference in the mean of peak RBS and 24 hours mean RBS of the non-survivors and survivors was $<0.005$ and hence significant. Statistical Analysis: Independent student $t$ test used for analysis. Conclusion: Hyperglycemia during first 24 hours of PICU admission was associated with higher mortality rate and longer duration of PICU stay.
\end{abstract}

Keywords: Hyperglycemia, Mortality, Critically ill, Glucose, Pediatric intensive care unit.

\section{Introduction}

Homeostasis is the internal milieu that must be maintained within a critical range for the machinery of life. Critical illness threatens this homeostasis. This belief underlines the strategy of setting physiologic goals and initiating "goal directed therapy" [1]. Instability of homeostatic mechanisms, functional immaturity of the vital organs and occurrence of multiple problems simultaneously in critically ill children lead to development of a complex clinical syndrome involving multiple body organs affecting the outcome adversely.

One of the most important part of homeostasis is the blood glucose level. Glucose is the major source of energy. Hence management of glucose level is critical in PICU management. Stress hyperglycemia was

Manuscript received: $10^{\text {th }}$ March 2016

Reviewed: $24^{\text {th }}$ March 2016

Author Corrected; $11^{\text {th }}$ April 2016

Accepted for Publication: $24^{\text {th }}$ April 2016 considered to be a beneficail adaptive response with a raised blood glucose providing a ready source of fuel for the brain, skeletal muscle, heart and other vital organs at a time of increased metabolic demand. On the other hand, it has been associated with complications prolonged ICU and hospital stay and increased mortality [2].

Hyperglycemia in the sick, nondiabetic patient was first described in the nineteenth century by Claude Bernard [3]. Stress diabetes, traumatic diabetes, or diabetes of injury was thought of an adaptive response and the rise in sugar was thought to represent the body's attempt to provide an adequate energy source to combat stress. Previously hyperglycemia was considered simply a marker of illness severity that required no significant intervention unless glucosuria occurs [4]. However, with the publication of the landmark study by Van den Berghe et al. in 2001 [5], compelling data suggest that 
high glucose levels are deleterious, and strict glycemic control is warranted to improve outcome in critically ill patients.

The landmark study on hyperglycemia in critically ill children was done by Srinivasan et al [6] published in 2004 which reported that hyperglycemia at 24 hours was present in $54 \%$ of the patients and was associated with a 3.5 fold higher mortality risk in PICU patients. This study is intended to throw light on the prevalence and relation of hyperglycemia with the outcome of the critically ill children admitted in our hospital.

\section{Aims and Objectives}

1. To study the prevalence of hyperglycemia in critically ill children admitted in PICU.

2. To study the association of hyperglycemia with PICU mortality and morbidity in terms of duration of PICU stay.

\section{Materials and Method}

Design: This study was a prospective observational study conducted in PICU of M. Y. Hospital, Indore (tertiary center), from $1^{\text {st }}$ of May 2011 to $15^{\text {th }}$ September 2011 over a period of four and half months.

Criteria for selection/rejection: All the critically ill children, belonging to age group of 1 month to 14 years, admitted in PICU in the above mentioned period, were included who fulfilled any of the following criteria:

a. Required mechanical ventilation.

b. Required vasoactive infusions either dopamine, dobutamine, epinephrine or norepinephrine.

c.Were suspected of having any CNS infections like tubercular meningoencephalitis, viral encephalitis, pyogenic meningitis or cerebral malaria.

All those children who were known diabetis mellitus patients or were diagnosed to have diabetis mellitus were excluded from the study.

Method: After taking the informed consent of the parents or guardians, children fulfilling the inclusion criteria were included in the study.

A detailed history and thourogh examination was done. All the relevant investigations were done. The children were followed throughout their hospital stay and their outcome in terms of mortality and duration of PICU stay were noted down. The treatment history of the children with details of mechanical ventilation, vasoactive infusions, steroids and medications which are given in dilution with dextrose solutions, were also noted.

Blood glucose estimation was done every 3 hourly during the first 48 hours of PICU admission. The first sample and the last sample for glucose estimation were sent to central laboratory. This was random serum glucose value. The remaining blood glucose values were obtained bedside with the help of glucometer (SD check gold). These were capillary whole blood glucose values. The highest blood glucose level in the first 48 hours was defined as the peak glucose level. The mean of the glucose values of the first 24 hours and first 48 hours were calculated.

Definition of blood glucose levels: As there has been no consensus over the threshold for stress hyperglycemia in critically ill children, for the purpose of this study, similar levels were taken as criteria for normoglycemia and hyperglycemia as was taken in the study done by Srinivasanetal. in 2004. [6].

This was also based on the criteria for the diagnosis of diabetes mellitus as determined by World Health Organisation and American Diabetes association.

\begin{tabular}{|c|c|}
\hline Glycemic State & RBS value \\
\hline Normo/euglycemia & $61-110 \mathrm{mg} / \mathrm{dl}$ \\
\hline Hyperglycemia & $\geq 126 \mathrm{mg} / \mathrm{dl}$ \\
\hline Hypoglycemia & $\leq 60 \mathrm{mg} / \mathrm{dl}$ \\
\hline Abnormal glucose tolerance & $111-125 \mathrm{mg} / \mathrm{dl}$ \\
\hline
\end{tabular}




\section{Results}

The prospective observational study was undertaken in the PICU of MY hospital, Indore for a period of four and half months, from May 2011 to $15^{\text {th }}$ September 2011. Total of 50 critically ill children were included and their regular blood glucose monitoring was done over the first 48 hours of PICU admission.

The prevalence of hyperglycemia was $58 \%$. The mortality rate was higher in the hyperglycemic patients (56\%) as compared to normoglycemics (14\%) and over all mortality (36\%). The p value for the difference in the mean of peak RBS and 24 hours mean RBS of the non-survivors and survivors was $<0.005$ and hence significant. The $p$ value for the difference in mean duration of PICU stay of the hyperglycemics and normoglycemics was 0.001 and was also significant.

Table 1: Distribution of patients according to over all mortality rate.

\begin{tabular}{|c|c|}
\hline Over All Mortality & Total no. of patients \\
\hline Survivor & 32 \\
\hline Death & 18 \\
\hline
\end{tabular}

Out of total 50 patients, 18 patients died with a mortality rate of $36 \%$.

Table 2: Distribution of patients according to diagnosis:

\begin{tabular}{|c|c|}
\hline Diagnosis & Total no. of patients \\
\hline CNS infections & 29 \\
\hline Congestive heart failure & 05 \\
\hline Septicemic shock & 08 \\
\hline Scorpion sting & 02 \\
\hline Encephalopathy & 01 \\
\hline Snake bite & 01 \\
\hline GuillaineBarre syndrome & 01 \\
\hline Status Epilepticus & 01 \\
\hline Moya-Moya disease & 02 \\
\hline
\end{tabular}

29 patients $(58 \%)$ had CNS infections, 8 cases (16\%) had septicemic shock while $10 \%$ (5 cases) were of congestive heart failure. There were 2 cases each of scorpion sting and encephalopathy.

Table 3: Distribution of patients according to peak RBS value.

\begin{tabular}{|c|c|c|}
\hline RBS Value & Total & Death \\
\hline$\leq 60 \mathrm{mg} / \mathrm{dl}$ & 1 & 0 \\
\hline $61-110 \mathrm{mg} / \mathrm{dl}$ & 14 & 3 \\
\hline $111-125 \mathrm{mg} / \mathrm{dl}$ & 6 & 1 \\
\hline $126-150 \mathrm{mg} / \mathrm{dl}$ & 0 & 13 \\
\hline $151-200 \mathrm{mg} / \mathrm{dl}$ & 7 & 22 \\
\hline
\end{tabular}

29 patients (58\%) had hyperglycemia, 14 patients had normoglycemia (28\%), 1 had hypoglycemia (2\%) and rest 6 had abnormal glucose tolerance (12\%). 14 out of total 29 hyperglycemic patients died (48\%). None of the normoglycemic patient died. The only hypoglycemic patient also died. The mortality rate in mild hyperglycemia $(126-150 \mathrm{mg} / \mathrm{dl}) \mathrm{was}$ none, in moderate hyperglycemia $(151-200 \mathrm{mg} / \mathrm{dl})$ was $14 \%$ while with severe (>200 mg dl) it was $59 \%$. 
Table 4: Distribution of patients according to mean 24 hours RBS:

\begin{tabular}{|c|c|c|}
\hline Mean 24 hours RBS & Total & Death \\
\hline$\leq 60 \mathrm{mg} / \mathrm{dl}$ & 1 & 3 \\
\hline $61-110 \mathrm{mg} / \mathrm{dl}$ & 21 & 0 \\
\hline $111-125 \mathrm{mg} / \mathrm{dl}$ & 3 & 2 \\
\hline $126-150 \mathrm{mg} / \mathrm{dl}$ & 4 & 2 \\
\hline $151-200 \mathrm{mg} / \mathrm{dl}$ & 5 & 10 \\
\hline$>200 \mathrm{mg} / \mathrm{dl}$ & 16 & 10 \\
\hline
\end{tabular}

25 patients (50\%) had hyperglycemia out of which 14 died (56\%). 21 patients had normoglycemia out of which 3 (14.2\%) died. One patient had hypoglycemia and he died, while rest 3 had abnormal glucose tolerance but all survived. The mortality rate with mild hyperglycemia was $50 \%$ with moderate hyperglycemia was $40 \%$ and severe hyperglycemia was $62.5 \%$

Table 5: Random blood sugar levels in survivors \& non survivors.

\begin{tabular}{|c|c|c|c|}
\hline & Non survivors & Survivors & P value \\
\hline Peak RBS & $252.78 \pm 116.44$ & $167.78 \pm 97.83$ & 0.008 \\
\hline Mean RBS 24 hours & $186.96 \pm 70.83$ & $132.48 \pm 68.80$ & 0.011 \\
\hline
\end{tabular}

This table shows that $\mathrm{p}$ value for the difference between mean of peak RBS among the survivors and non-survivors is significant. Likewise the $\mathrm{p}$ value for the difference between mean of Mean of 24 hours RBS among the survivors and non-survivors is also significant.

Table 6:

\begin{tabular}{|c|c|c|c|}
\hline PICU Stay & Hyperglycemia & Normoglycemia & p value \\
\hline Peak RBS & $6.88 \pm 2.17$ & $4.43 \pm 2.27$ & 0.005 \\
\hline Mean 24 hours & $7.18 \pm 1.53$ & $4.50 \pm 2.5$ & 0.004 \\
\hline Mean 48 hours & $6.83 \pm 1.32$ & $5.09 \pm 2.6$ & 0.132 \\
\hline
\end{tabular}

This table no. 4 shows that the p value of duration of PICU stay between the hyperglycemic and normoglycemic patients, according to peak RBS and Mean 24 hours RBS is significant but of mean 48 hours is not significant.

\section{Discussion}

Serum glucose levels were measured in children during study period and highest value was assessed in relation to outcome of the patients. The prevalence of hyperglycemia was $58 \%$ (29 out of 50) with mean peak glucose level of $198.38 \pm 111.61 \mathrm{mg} / \mathrm{dl}$ and mortality rate of $36 \%$ (18 out of 50 ). In non-survivors, peak glucose level was $252.78 \pm 116.44 \mathrm{mg} / \mathrm{dl}$, which was higher $(\mathrm{p}=0.004)$ than that found in survivors $167.18 \pm$ $97.83 \mathrm{mg} / \mathrm{dl}$. Mortality rate increased with increasing intensity of hyperglycemia, i.e. with mild hyperglycemia $(126-150 \mathrm{mg} / \mathrm{dl})$ there was no death, with moderate hyperglycemia (151-200 mg/dl) the mortality rate was $14 \%$, but with severe hyperglycemia (201-500 mg/dl) it was 59\%.

Srinivasan e tal [6] in their study found hyperglycemia in $86 \%$ patients according to peak RBS and in $54 \%$ patients according to mean 24 hours RBS value.
Faustino et al.[7] found the prevalence of hyperglycemia varying from $16.7 \%$ to $75 \%$ according to three different cut off values of $>120 \mathrm{mg} / \mathrm{dl},>150$ $\mathrm{mg} / \mathrm{dl}$ and $>200 \mathrm{mg} / \mathrm{dl}$. Hirschberg et al., [8] found hyperglycemia in $56.1 \%$ patients taking cut off value as $>150 \mathrm{mg} / \mathrm{dl}$ and hypoglycemia in $9.7 \%$ patients. In our study only $2 \%$ patients had hypoglycemia and $58 \%$ had hyperglycemia. In one retrospective cohort study by Sarah B. Kandil et al [9] and S Ranjit et al [10] mean blood glucose in treatment group was $140+/-24 \mathrm{mg} / \mathrm{dl}$ compared with $179+/-47 \mathrm{mg} / \mathrm{dl}$ in baseline group $(\mathrm{p}<0.001)$.

The $\mathrm{p}$ value for the difference between the mean RBS values in nonsurvivors and survivors was significant in our study which was also found significant in the study done by Srinivasan et al. [6]. Likewise the duration of PICU stay of hyperglycemic patients was prolonged in 
both the studies. Although we found that the mortality rate among the hyperglycemics was higher than that of normoglycemics but we did not calculate the odd's ratio or relative risk. So we are not able to accurately compute the exact rise in risk of mortality in presence of hyperglycemia.

Previous study of Srinivasan et al. found that the risk of mortality increases 3.5 folds with hyperglycemia [6].

In our study 1 patient was found hypoglycemic. This patient had septicemic shock and had lower blood glucose level, probably due to severe failure to thrive status. He was 8 months old, top fed, with weight of 2.5 $\mathrm{kg}$.

Role of iatrogenic factors, like use of steroids, dextrose diluted medications etc. in hyperglycemia, cannot be completely ruled out. Although in our study 11 patients were given steroids out of whom $45.45 \%$ had hyperglycemia and normoglycemia each and rest $9 \%$ had blood glucose level in abnormal glucose tolerance range.

\section{Conclusion}

Hyperglycemia in critically ill children is not uncommon, but is usually underappreciated considering is to be a beneficial stress response. But accepting hyperglycemia as an adaptive response to critical illness and treating it only when it crosses renal threshold, is not justified.

Intense hyperglycemia during first 24 hours of PICU admission was associated with higher mortality rate and a longer duration of PICU stay in our study.

Thus, based on the data presented in this study, a prospective, randomized trial of strict glycemic control in critically ill children, who are at higher risk of mortality is required. Each PICU should implement locally appropriate protocols of blood glucose control alongwith other critical care.

Funding: Nil, Conflict of interest: Nil

Permission from IRB: Yes

\section{Bibliography}

1. Tasker RC. Pediatric critical care, glycemic control, and hypoglycemia: what is the real target? JAMA. 2012 Oct 24;308(16):1687-8.

2. Marik PE. Glycemic control in critically ill patients: What to do post NICE-SUGAR? World J Gastrointest Surg. 2009 Nov 30;1(1):3-5. doi: 10.4240/wjgs.v1.i1.3.

3. Van den Berghe G. How does blood glucose control with insulin save lives in intensive care? J Clin Invest. 2004 Nov;114(9):1187-95.

4. Roger's textbook on Intensive Pediatric Care- $4^{\text {th }}$ edition-1605-1614

5. van den Berghe G, Wouters P, Weekers F, Verwaest C, Bruyninckx F, Schetz M, Vlasselaers D, Ferdinande $\mathrm{P}$, Lauwers P, Bouillon R. Intensive insulin therapy in critically ill patients. N Engl J Med. 2001 Nov 8;345(19):1359-67.

6. Srinivasan V, Spinella PC, Drott HR, Roth CL, Helfaer MA, Nadkarni V. Association of timing, duration, and intensity of hyperglycemia with intensive care unit mortality in critically ill children. Pediatr Crit Care Med. 2004 Jul;5(4):329-36.

7. Faustino EV, Apkon M. Persistent hyperglycemia in critically ill children. J Pediatr. 2005 Jan;146(1):30-4.

8. Hirschberg E, Larsen G, van Duker H: Alterations in glucose homeostasis in the pediatric intensive care unit : hyperglycemia and glucose variability are associated with increased mortality and morbidity: Pediatric Critical Care Medicine:2008:9: 361-366.

9. Kandil SB, Spear D, Thomas NJ, Weinzimer SA, Faustino EV. Retrospective outcomes of glucose control in critically ill children. J Diabetes Sci Technol. 2013 Sep 1;7(5):1220-8.

10. Ranjit S. Hyperglycemia in the pediatric intensive care unit: Innocent bystander or villain of the piece? Indian J Crit Care Med. 2014 Jan;18(1):6-7. doi: 10. 4103/0972-5229.125424.

\section{How to cite this article?}

Jain H, Arya S, Mandloi R.The prevalence of hyperglycemia in critically ill children admitted in PICU. Int J Pediatr Res.2016;3(6):467-471.doi:10.17511/ijpr.2016.i06.16. 